OPEN ACCESS

Edited by:

Surendra Dara,

University of California System,

United States

Reviewed by:

Patricia Golo,

Federal Rural University of Rio de Janeiro, Brazl

Steven Arthurs,

Independent Researcher, Salisbury

United States

*Correspondence:

Ítalo Delalibera Jr.

delalibera@usp.br

Specialty section:

This article was submitted to

Crop Biology and Sustainability,

a section of the journal

Frontiers in Sustainable Food Systems

Received: 14 February 2020

Accepted: 30 July 2020

Published: 15 September 2020

Citation:

Siqueira ACO, Mascarin GM,

Gonçalves CRNCB, Marcon J, Quecine MC, Figueira A and Delalibera

I Jr (2020) Multi-Trait Biochemical

Features of Metarhizium Species and

Their Activities That Stimulate the

Growth of Tomato Plants.

Front. Sustain. Food Syst. 4:137.

doi: 10.3389/fsufs.2020.00137

\section{Multi-Trait Biochemical Features of Metarhizium Species and Their Activities That Stimulate the Growth of Tomato Plants}

\author{
Ana Carolina Oliveira Siqueira', Gabriel Moura Mascarin ${ }^{2}$, \\ Cassiara R. N. C. B. Gonçalves ${ }^{1}$, Joelma Marcon ${ }^{3}$, Maria Carolina Quecine ${ }^{3}$, \\ Antonio Figueira ${ }^{4}$ and Ítalo Delalibera $\mathrm{Jr}^{1 *}$ \\ ${ }^{1}$ Department of Entomology and Acarology, "Luiz de Queiroz" College of Agriculture/University of São Paulo (ESALQ/USP), \\ Piracicaba, Brazil, ' ${ }^{2}$ Laboratory of Environmental Microbiology, Brazilian Agricultural Research Corporation, Embrapa \\ Environment (EMBRAPA), Jaguariúna, Brazil, ${ }^{3}$ Department of Genetics, "Luiz de Queiroz" College of Agriculture/University of \\ São Paulo (ESALQ/USP), Piracicaba, Brazil, ${ }^{4}$ Center for Nuclear Energy in Agriculture/University of São Paulo (CENA/USP), \\ Piracicaba, Brazil
}

The interaction between Metarhizium spp. and plant roots may induce host plant growth and help control below- and above-ground pests and diseases. We conducted in vivo and in vitro bioassays using native Brazilian isolates of Metarhizium robertsii (ESALQ 1635), M. humberi (ESALQ 1638), and M. anisopliae (ESALQ 1669) to better understand the possible mechanisms related to plant growth promotion traits and colonization of the root system in the model pot-grown tomato (Solanum lycopersicum L.) miniature cultivar "Micro-Tom." In vivo trials revealed that M. robertsii (ESALQ 1635) or M. humberi (ESALQ 1638) inoculated in tomato seedlings improved vegetative and reproductive traits. Inoculation with $M$. robertsii yielded taller plants, longer roots, and more shoot and root dry mass than $M$. humberi. The number of flowers and the fresh weight of fruits was significantly increased by $M$. robertsii and $M$. humberi inoculation, in relation to uninoculated control plants. Both fungal species endophytically colonized all tomato tissues within 30 days of inoculation. Plants inoculated with either $M$. robertsii or $M$. humberi increased auxin-induced GUS expression in the roots for up to 30 days after inoculation, confirming that Metarhizium induces auxin-regulated gene expression. We also explored the production of key compounds including enzymes, hormones, and metabolites involved in plant growth promotion. The three Metarhizium species grown with or without exogenous tryptophan were able to produce indole-3-acetic acid (IAA) at different titers. All Metarhizium isolates produced phosphatases, phytases, siderophores, and chitinases. Of particular importance, the $M$. robertsii and $M$. humberi isolates exhibited similar in vitro biochemical profiles, whereas $M$. anisopliae and Trichoderma harzianum isolates demonstrated distinct traits from the others. Taken together, we argue that the $M$. robertsii isolate is more efficient than the $M$. humberi isolate to endophytically colonize tomato plants resulting in improved growth. However, M. humberi (ESALQ 1638) yielded a slightly better production of some metabolites in vitro. Thus, 
we propose that the isolates of $M$. robertsii and $M$. humberi could be explored as complementary plant growth promoters.

Keywords: endophytes, plant growth promotion, GUS, IAA, phosphate solubilization, siderophores, phytases, chitinases

\section{INTRODUCTION}

Endophytes may benefit plants through protecting against insect pests and promoting growth. Attempts to use fungi as endophytes in plants have been tested as a novel strategy for pest control (Jaber and Ownley, 2017). Entomopathogenic fungi as endophytes stand out as a prospective approach for plant protection, inducing resistance against insect pests and consequently reduced pesticide use (Vidal and Jaber, 2015). Metarhizium spp., a group of soil-borne fungi, are biocontrol agents of insects, arachnids, and other arthropod pests. Beyond their well-established entomopathogenic lifestyle, Metarhizium are ubiquitous, free-living fungi that inhabit predominantly the soil and can colonize plant roots, which may improve plant growth (Roberts and St. Leger, 2004; Behie and Bidochka, 2014; Vega, 2018).

Some plant growth-promoting fungi (PGPF) can promote plant growth and health after inoculation (Elsharkawy and ElKhateeb, 2019) by stimulating several biological mechanisms, including the production of hormones, such as auxins (Bose et al., 2013), solubilization of phosphate (Barrow and Osuna, 2002) and the production of siderophores (Bartholdy et al., 2001) or chitinases (Caldwell et al., 2000). These mechanisms possibly associated with plant growth promotion have been demonstrated for some PGPF, but have been overlooked for the entomopathogenic fungus Metarhizium.

Indole-3-acetic acid (IAA), the most common auxin, regulates plant growth and development. Some microorganisms possess the ability to synthesize IAA to boost plant growth (NietoJacobo et al., 2017). Besides, IAA may improve the colonization efficiency of endophytic fungi. The PGPF can affect the endogenous levels of IAA, consequently improving plant nutrition and growth (Jha and Saraf, 2015).

Plant-growth-promoting microorganisms, such as fungi, can also mineralize and solubilize organic phosphorus into inorganic forms by producing enzymes called phytases and phosphatases, which then become available for plant uptake (Singh and Satyanarayana, 2011; Ghosh et al., 2015). P solubilization is fundamental for plant growth and development. Organic P reserve in soil ranges from 5 to $95 \%$ of the total soil P, of which phytate constitutes up to 50\% (Dalai, 1977). Although phosphate is abundantly available in the soil, plants can only use inorganic phosphate, which is the soluble form (Khan et al., 2010).

Entomopathogenic fungi use chitinases to enter their hosts by directly penetrating the cuticle (Samuels et al., 1989). Chitinase is also linked to the process of endophyte colonization in plants (Kauss et al., 1983). Chitin is an important component of the eggshell of nematodes, and chitin synthesis is a process maintained across the fungal kingdom. Production of chitinase by PGPF can indirectly contribute to plant growth by reducing insects, plant pathogens, and nematode populations (Furtado et al., 2019).

Siderophores are low biomolecular weight $(0.5-1.5 \mathrm{kDa})$ ironchelating compounds, which are produced by microorganisms with a high affinity for $\mathrm{Fe}^{+3}$, and can mediate iron $(\mathrm{Fe})$ uptake into the microbial cells (Gupta et al., 2015). Siderophores can contribute to plant growth and development, as well as improve the acquisition of $\mathrm{Fe}$ and other essential micronutrients in plants (Raya-Díaz et al., 2017). The inorganic form of Fe in the soil is not readily assimilated by plants (Kobayashi and Nishizawa, 2012). However, siderophores can chelate Fe through a biochemical mechanism of reducing inorganic $\mathrm{Fe}^{+3}$ to $\mathrm{Fe}^{+2}$, which then becomes available for root uptake (Grobelak et al., 2015). For plant nutrition and health, Fe participates as a component in many enzymatic systems, including those associated with plant defenses, and is intrinsically involved in the major process of chlorophyll synthesis (Rout and Sahoo, 2015). PGPF can also indirectly affect plant growth through the chelating property of siderophores by making Fe less available to other competing microorganisms, and thus negatively affect their growth, including plant pathogens (Parmar and Chakraborty, 2016).

Therefore, our main objectives of this study focused on the biochemical characterization of Brazilian Metarhizium spp. isolates, including the production of IAA, siderophores, chitinases, phytases, and phosphatases for phosphorus solubilization, alongside the effects on tomato miniature cultivar Micro-Tom (MT), inoculated with two root colonizers, M. robertsii and M. humberi sp. nov. Luz et al. (2019), on growth promotion, fruit yield, and auxin accumulation in roots. The MT transgenic reporter tomato line is a useful phenotype to investigate IAA signaling through visualization of root parts based on the activity of $\beta$-glucuronidase (Blanco et al., 1982), confirming that both $M$. humberi and M. robertsii induced endogenous IAA production. These findings support the commercial development of both indigenous isolates of $M$. robertsii and $M$. humberi as biocontrol agents and root colonizers for stimulating plant growth.

\section{MATERIALS AND METHODS}

\section{Fungal Isolates}

All assays were conducted in the "Insect Pathology and Microbial Control Laboratory" at the Entomology Department, in the "Prof. João Lúcio de Azevedo" Laboratory at the Genetics Department both at ESALQ/USP and at Plant Breeding Laboratory at Center for Nuclear Energy in Agriculture/University of São Paulo (CENA/USP). One isolate of each of the endophytic entomopathogenic fungi M. robertsii, $M$. humberi, and M. anisopliae (Table 1) were used in this study. The 
TABLE 1 | Description of fungal isolates used in the experiments.

\begin{tabular}{|c|c|c|c|c|c|}
\hline Isolate code ${ }^{a}$ & Fungal species & Crop/Isolation method & Location in Brazil (City-State) ${ }^{b}$ & Geographical coordinates & Sampling date \\
\hline ESALQ 1635 & Metarhizium robertsii & Forest soil/Insect bait with Tenebrio molitor & Delmiro Gouveia, AL & $9^{\circ} 25^{\prime} 0.12^{\prime \prime} \mathrm{S} 37^{\circ} 57^{\prime} 8.49^{\prime \prime} \mathrm{W}$ & Mar/2012 \\
\hline ESALQ 1638 & Metarhizium humberi & Savanna soil/Selective media (PDAY) & Rio Verde, GO & $17^{\circ} 29^{\prime} 49.3^{\prime \prime S} 51^{\circ} 13^{\prime} 40.7^{\prime \prime} \mathrm{W}$ & Mar/2012 \\
\hline ESALQ 1669 & Metarhizium anisopliae & Sugarcane soil/Insect bait with T. molitor & Iracemápolis, SP & $22^{\circ} 36^{\prime} 10^{\prime \prime} \mathrm{S} 47^{\circ} 33^{\prime} 17^{\prime \prime} \mathrm{W}$ & Dec/2012 \\
\hline ESALQ 1306 & Trichoderma harzianum & Soil/Selective media (PDAY) & Piracicaba, SP & $22^{\circ} 42^{\prime} 06.7^{\prime \prime} \mathrm{S} 47^{\circ} 38^{\prime} 44.2^{\prime \prime} \mathrm{W}$ & Jul/2002 \\
\hline
\end{tabular}

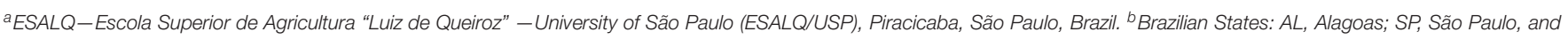
GO, Goiás.

isolates were deposited in "Prof. Sérgio Batista Alves" collection at ESALQ/USP and had been previously identified to species level by molecular techniques (Rezende et al., 2015; Botelho et al., 2019; Luz et al., 2019). M. robertsii and M. humberi, which are registered as biopesticides in Brazil, were selected for their effects on growth promotion of sugarcane plants (length of plants, increased roots, increase in chlorophyll content, and antagonism to sugarcane phytopathogens, and insect pests), which were demonstrated in our previous greenhouse and field studies (A.C.O. Siqueira, unpublished). The soil-borne and opportunistic plant symbiont T. harzianum isolate ESALQ 1306, deposited in the same collection at ESALQ/USP, was used as a standard control for comparisons in the biochemical assays (marketed by Koppert do Brasil Holding Ltd., Piracicaba, SP, Brazil). The access of these three Metarhizium species is registered at the Brazilian System for the Management of Genetic Heritage and Associated Traditional Knowledge-SisGen under the code RAC856E.

\section{Plant Material}

The tomato miniature cultivar Micro-Tom (MT) employed is considered a suitable genetic model (Meissner et al., 1997; Scott Harbaugh, 1989). The transgenic line DR5::GUS on the MT genetic background contains the auxin-responsive promoter of $D R 5$ fused to the reporter gene uid encoding a $\beta$-glucuronidase (GUS), which allows enzymatic staining of sites where auxin accumulates (Mart et al., 2010). The use of this reporter line is valuable to elucidate the role of Metarhizium in root colonization and to screen the best root-competent isolates.

\section{Plan Growth Promotion Tests}

Only M. robertsii (ESALQ 1635) and M. humberi (ESALQ 1638) isolates were selected due to limitations of the experimental setup and considering the superior plant growth promotion by both isolates in previous studies in our laboratory (A. C. Siqueira et al., unpublished). DR5::GUS seeds were sown on cell trays containing non-autoclaved Tropstrato HT substrate + expanded vermiculite (1:1), according to Lima et al. (2009). Conidia production, viability reading, and concentration adjustment were performed as described by Oliveira et al. (2015). The seedlings were kept in a greenhouse and irrigated daily. After 18 days of sowing, the seedlings were transplanted to $150 \mathrm{~mL}$ plastic pots. Fungal spores were inoculated by applying $1 \mathrm{~mL}$ of a $10^{8}$ conidia $\mathrm{mL}^{-1}$ suspension of Metarhizium spp. with $0.05 \%$ of Tween $80^{\circledR}(\mathrm{v} / \mathrm{v})$ at the base of each seedling using a sterile pipette for each fungal species. As a control, $1 \mathrm{~mL}$ of distilled water prepared with $0.05 \%$ of Tween $80^{\circledR}(\mathrm{v} / \mathrm{v})$ was applied to each plant. The experiment was conducted in a greenhouse and plants were exposed to the natural incidence of light. This entire assay was repeated independently twice and followed a completely randomized design. Within each assay, each treatment had 20 replicates. The average max and min daily temperatures during the course of this greenhouse experiment were 28.7 and $12.3^{\circ} \mathrm{C}$, respectively. The max, mean, and min relative humidity $(\mathrm{RH})$ were $96.1,71$, and $40.1 \%$, respectively, inside the greenhouse. Then, 10, 15, and 30 days after inoculation (DAI), the length of the shoot and roots were evaluated using a $50 \mathrm{~cm}$ ruler, and the diameter of the shoot was assessed using a digital caliper (Western ${ }^{\circledR}$ PRO, SP, Brazil). Shoots and roots were separated and dried in paper bags using a drying oven (Marconi, MA033, Piracicaba, SP, Brazil) at $60^{\circ} \mathrm{C}$ for $24 \mathrm{~h}$. After drying, the samples were weighed.

To assess the endophytism of these fungal species, plant materials from independent samples comprised of leaves, stems, and roots were collected 10, 15, and 30 DAI, cut into 3$\mathrm{cm}$ fragments and surface sterilized by immersion for $15 \mathrm{~s}$ in $70 \%$ ethanol, $50 \mathrm{~s}$ in $0.8 \%$ sodium hypochlorite, $15 \mathrm{~s}$ in $70 \%$ ethanol again, rinsed three times in sterile distilled water, and finally left to dry on sterile filter paper. The efficacy of the sterilization was confirmed by plating the last rinsing water $(100 \mu \mathrm{L})$ onto Potato Dextrose Agar (PDA) (Kasvi ${ }^{\circledR}$, Brazil) (Parsa et al., 2013). The plant samples were then placed in Petri dishes $(90 \times 15 \mathrm{~mm})$ containing selective medium composed of PDA, supplemented with $500 \mathrm{mg} \mathrm{L}^{-1}$ cycloheximide, $200 \mathrm{mg} \mathrm{L}^{-1}$ chloramphenicol, $500 \mathrm{mg} \mathrm{L}^{-1}$ Dodine $\left(65 \% \mathrm{w} / \mathrm{v}\right.$ Dodex $450 \mathrm{SC}^{\circledR}$ SIPCAM-AGRO, Brazil), $10 \mathrm{mg} \mathrm{L}^{-1}$ Crystal Violet (Dinâmica Analytical Reagents ${ }^{\circledR}$, SP, Brazil) (Behie et al., 2015). The cultures were incubated at $24^{\circ} \mathrm{C}$ for 15 days in darkness. There were three independent replicate tissues per plate and five plates for each fungal species. The presence of colonies was detected according to morphological characteristics of the fungal outgrowth in each plant fragment, and the fungal colonization rate was given by the number of fungus-colonized plant fragments divided for the number of fragments plated on a selective culture medium, multiplied by 100 .

In addition, the presence of the fungi in the soil was determined 10,15, and 30 DAI by preparing suspensions of soil substrate from where the plants had grown. Soil samples were obtained from the region near the plant from each replicate. A soil sample $(1.0 \mathrm{~g})$ from each pot was transferred to $10 \mathrm{~mL}$ sterile 
water with $0.05 \%$ Tween $80^{\circledR}(\mathrm{v} / \mathrm{v})$. The suspension was then vigorously vortexed and four consecutive ten-fold serial dilutions $\left(10^{-1}, 10^{-2}, 10^{-3}\right.$, and $\left.10^{-4}\right)$ were inoculated in Petri dishes $(90$ $\times 15 \mathrm{~mm}$ ) containing the selective agar media described above. The plates were divided into four equal quarters by marking the bottom of the Petri dish with a permanent marker and one aliquot $(20 \mu \mathrm{L})$ of each of the four dilutions was pipetted onto each quarter (Miles et al., 1938). The Petri dishes were incubated at $24^{\circ} \mathrm{C}$ for 15 days in darkness and the presence of colonies was detected according to morphological characteristics of the fungal outgrowth.

\section{Biochemical Assays IAA Production in vitro}

The in vitro production of IAA by $M$. robertsii (isolate ESALQ 1635), M. humberi (isolate ESALQ 1638), M. anisopliae (ESALQ 1669), and the T. harzianum (isolate ESALQ 1306-as a positive control) was determined in Potato Dextrose Broth (PDB) medium, amended or not with L-tryptophan $(0$ and $0.1 \mathrm{~g}$ $\mathrm{L}^{-1}$ ) (Labsynth ${ }^{\circledR}$, Diadema, SP, Brazil). Fungal cultures were established in $50 \mathrm{~mL}$ of liquid PDB media inoculated with three mycelia plugs $(\varnothing 0.7 \mathrm{~cm})$. The media were maintained in an orbital shaker incubator $\left(\right.$ Marconi ${ }^{\circledR}$, Piracicaba, SP, Brazil) at $150 \mathrm{rpm}$ for 7 days and $25 \pm 1^{\circ} \mathrm{C}$. After this incubation time, $1.5 \mathrm{~mL}$ of fungal broth was centrifuged at $10,000 \mathrm{~g}$, and the supernatant was collected. An aliquot $0.5 \mathrm{~mL}$ was mixed with $0.5 \mathrm{~mL}$ of Salkowski's reagent $\left(15 \mathrm{~mL} \mathrm{H}_{2} \mathrm{SO}_{4}, 0.75 \mathrm{~mL} \mathrm{FeCl}_{3}\right.$, and $25 \mathrm{~mL}$ distilled water) (Gordon and Weber, 1951). The reaction was performed in the dark for $30 \mathrm{~min}$ and subsequently read with an optical density (O.D.) at $530 \mathrm{~nm}$ in a spectrophotometer (Amersham Pharmacia Biotech, Ultrospec 3000, Little Chalfont, UK). The standard curve was obtained by diluting $10 \mathrm{mg}$ of a commercial synthetic auxin (CAS: 87-51-4, purity > $98 \%$, Sigma ${ }^{\circledR}$, Germany) in $10 \mathrm{~mL}$ acetone. Concentrations of commercial IAA were adjusted to $0,1,5,10$, and $20 \mu \mathrm{g} \mathrm{mL}^{-1}$ using PDB to determine the standard concentration-absorbance curve (Etesami et al., 2015). This assay followed a completely randomized design and was conducted three times using new fungal batches. In each independent assay, fungal treatments were evaluated in triplicates (i.e., Erlenmeyer flasks containing fungal liquid cultures).

\section{IAA Production in vivo}

To confirm the role of auxin in growth stimulation by inoculation with the Metarhizium spp., and to locate the tissue with more effective auxin signaling and/or accumulation, the DR5::GUS transgenic line was inoculated by applying a conidia suspension at the base of the seedlings with the two Metarhizium isolates. Histochemical assays for $\beta$-glucuronidase (GUS) activity detection were performed according to Jefferson et al. (1987) after 10 and 30 DAI with $M$. robertsii (ESALQ 1635) and $M$. humberi (ESALQ 1638). Roots of tomato plants inoculated and non-inoculated were separated from the plants and washed in running water to remove excess substrate, followed by immersion in the GUS buffer $\left[100 \mathrm{mM} \mathrm{NaH} \mathrm{PO}_{4} .7 \mathrm{H}_{2} \mathrm{O} \mathrm{pH}\right.$ 7.0, $10 \mathrm{mM}$ EDTA pH 7.0, $0.5 \mathrm{mM} \mathrm{K} \mathrm{K}_{3} \mathrm{Fe}(\mathrm{CN})_{6} \mathrm{pH} 7.0,0.5 \mathrm{mM}$
$\mathrm{K}_{4}\left[\mathrm{Fe}(\mathrm{CN})_{4}\right] .3 \mathrm{H}_{2} \mathrm{O}$ pH 7.0, 0.1\% Triton X-100, 1 mM 5-bromo4-chloro-3-indolyl glucuronide-X-Gluc (Jersey Lab and Glove Supply, Livingston, NJ, USA)]. The samples immersed into GUS buffer were submitted to 600 bar vacuum for $5 \mathrm{~min}$, followed by incubation at $37^{\circ} \mathrm{C}$ with $100 \mathrm{rpm}$ of orbital shaking in total darkness for $24 \mathrm{~h}$. Images of the roots were captured using the Leica ${ }^{\circledR}$ stereomicroscope 205C (Leica Microsystems, Wetzlar, Germany) and analyzed using LAV4.5 software. The assay was conducted three times and in each independent assay, five plants per treatment were evaluated (biological replicates) for GUS activity.

\section{Determination of in vitro Phosphate Solubilization}

Phosphate solubilization activity was determined by a plate assay using the culture medium described by Pikovskaya (1948). The media were placed in Petri dishes $(90 \times 15 \mathrm{~mm})(20 \mathrm{~mL})$ and inoculated at the center of the plate with a three-day oldgrowth disc $(\varnothing 0.7 \mathrm{~cm})$. The positive control was $T$. harzianum (ESALQ 1306), while M. anisopliae (ESALQ 1669) was used for comparison. Plates were incubated at $25^{\circ} \mathrm{C}, 12 \mathrm{~h}$ photophase and $60 \% \mathrm{RH}$. Measurements of fungal colony diameter and the diameter of the surrounding transparent halo were taken at $15 \mathrm{DAI}$, and both parameters were used as indicative of phosphorus solubilization. The Phosphate Solubilization Index (FSI) was expressed by: FSI $=\varnothing$ halo/ $\varnothing$ colony. This assay followed a completely randomized design with five replicates (plates) and was repeated three times on different occasions to ensure reproducibility.

\section{Determination of Phytase Production}

Fungal phytase production was evaluated using a modified phytate screening medium (Howson and Davis, 1983), containing $5 \mathrm{~g} \mathrm{~L}^{-1}$ of $\mathrm{NH}_{4} \mathrm{NO}_{3} ; 0.5 \mathrm{~g} \mathrm{~L}^{-1}$ of $\mathrm{MgSO}_{4} .7 \mathrm{H}_{2} \mathrm{O}$; $0.5 \mathrm{~g} \mathrm{~L}^{-1}$ of $\mathrm{KCl} ; 0.01 \mathrm{~g} \mathrm{~L}^{-1}$ of $\mathrm{FeSO}_{4} .7 \mathrm{H}_{2} \mathrm{O} ; 0.01 \mathrm{~g} \mathrm{~L}^{-1}$ of $\mathrm{MnSO}_{4} .4 \mathrm{H}_{2} \mathrm{O} ; 5 \mathrm{~g} \mathrm{~L}^{-1}$ of calcium phytate $\left(\mathrm{C}_{6} \mathrm{H}_{18} \mathrm{O}_{24} \mathrm{P}_{6}\right)$; $15 \mathrm{~g} \mathrm{~L}^{-1}$ of glucose; $15 \mathrm{~g} \mathrm{~L}^{-1}$ of agar. The medium $\mathrm{pH}$ was adjusted to 5.5. A fungal growth disc $(\varnothing 0.7 \mathrm{~cm})$ from three-day-old mycelia was inoculated onto the center of the Petri dishes $(90 \times 15 \mathrm{~mm})$, containing $20 \mathrm{~mL}$ of the medium. Fungal cultures of the M. robertsii (ESALQ 1635), M. humberi (ESALQ 1638), and M. anisopliae (ESALQ 1669) isolates and the control T. harzianum (ESALQ 1306) were incubated at $25^{\circ} \mathrm{C}, 12 \mathrm{~h}$ photophase, and $60 \% \mathrm{RH}$. Measurements were taken at $15 \mathrm{DAI}$ and expressed as fungal diameter and the transparent halo diameter, as indicative of phytate solubilization. The phytase activity was determined according to the Phytase Degradation Index (PDI), calculated as: $\mathrm{PDI}=\varnothing$ halo/ $\varnothing$ colony. This assay was repeated three times and followed a completely randomized design with five replicates (plates).

\section{Determination of Siderophore Production}

To investigate the siderophore production of Metarhizium spp., the Chromoazurol S (CAS) analysis was used (Schwyn and Neilands, 1987). All glassware used during the analysis was previously immersed in a $6.0 \mathrm{M} \mathrm{HCl}$ solution overnight to ensure the removal of all traces of iron that could have 
been present. For the indicator solution, $60.5 \mathrm{mg}$ of CAS was dissolved in $50 \mathrm{~mL}$ of ultra-pure water and mixed with $10 \mathrm{~mL}$ of Iron (III) $\left(1 \mathrm{mM} \mathrm{FeCl} 3 \cdot 6 \mathrm{H}_{2} \mathrm{O}\right.$ in $\left.10 \mathrm{mM} \mathrm{HCl}\right)$. Under stirring, this solution was slowly added to $72.9 \mathrm{mg}$ of HDTMA (Hexadecyltrimethylammonium) dissolved in $40 \mathrm{~mL}$ of ultrapure water. These solutions were autoclaved separately. The irondeficient culture medium MM9 (Payne, 1994) contained $1.0 \mathrm{~g}$ $\mathrm{NH}_{4} \mathrm{Cl}, 0.3 \mathrm{~g} \mathrm{KH}_{2} \mathrm{PO}_{4}, 0.5 \mathrm{~g} \mathrm{NaCl}, 1.2 \mathrm{~g}$ piperazine $\left(\mathrm{C}_{4} \mathrm{H}_{10} \mathrm{~N}_{2}\right)$, and $18.0 \mathrm{~g}$ agar, completed to $1 \mathrm{~L}$ with ultra-pure water, with initial $\mathrm{pH}$ set to 5.6. The CAS solution was added, mixed into the MM9 medium, and placed in Petri dishes. A fungal growth disc $(\varnothing 0.7 \mathrm{~cm})$ from three-day-old fungal mycelia was inoculated at the center of the Petri dishes $(90 \times 15 \mathrm{~mm})$. Fungal cultures of the three Metarhizium spp. isolates and the control T. harzianum were incubated at $25^{\circ} \mathrm{C}, 12 \mathrm{~h}$ photophase, and $60 \%$ $\mathrm{RH}$. The changing of the blue color of the CAS medium to yellow indicates the production of siderophores. Measurements were taken at 15 DAI based on the yellow halo and the fungal colony diameter. The Siderophore Production Index (SPI) was determined according to the SPI $=\varnothing$ halo/ $\varnothing$ colony. This assay was repeated three different times and followed a completely randomized design with five replicates (plates).

\section{Determination of Chitinase Production}

To investigate the chitinase production by M. robertsii (ESALQ 1635), M. humberi (ESALQ 1638), M. anisopliae (ESALQ 1669), and the control T. harzianum (ESALQ 1306), the media contained $3.0 \mathrm{~g}\left(\mathrm{NH}_{4}\right)_{2} \mathrm{SO}_{4} ; 2.0 \mathrm{~g} \mathrm{KH}_{2} \mathrm{PO}_{4} ; 0.3 \mathrm{~g} \mathrm{MgSO} 4 ; 1.0 \mathrm{~g}$ citric acid, $4.5 \mathrm{~g}$ Sigma ${ }^{\circledR}$ colloidal chitin; $15.0 \mathrm{~g}$ agar; in $1 \mathrm{~L}$ of distilled water, with $\mathrm{pH}$ adjusted to 4.8 , and supplemented with $0.15 \mathrm{~g}$ of bromocresol purple (Agrawal and Kotasthane, 2012). A fungal growth disc $(\varnothing 0.7 \mathrm{~cm})$ from three-day-old fungal mycelia was inoculated at the center of the Petri dishes $(90 \times 15 \mathrm{~mm})$. Fungal cultures of the three isolates of Metarhizium spp. and the control T. harzianum (ESALQ 1306) were incubated at $25^{\circ} \mathrm{C}, 12 \mathrm{~h}$ photophase, and $60 \% \mathrm{RH}$. The diameter of both the fungal colony and purple colored chitin degradation halo were each measured at $15 \mathrm{DAI}$, to calculate the Chitin Degradation Index (CDI), expressed by: $\mathrm{CDI}=\varnothing$ halo/ $\varnothing$ colony. This assay was repeated three different times and followed a completely randomized design with five replicates (plates).

\section{Data Analysis}

Goodness-of-fit was assessed using half-normal plots with simulation envelopes (Moral et al., 2017). All analyses were carried out in R Core Team (2018). Linear mixed models (assuming a normal distribution for the error) were fitted to the IAA production, including the effects of experiment and the interaction term between fungal species and amino acid precursor in the linear predictor, as well as with random replicates. Similarly, continuous data recorded for enzyme activities (phytases, phosphatases, chitinases, and siderophores) were separately fitted to linear mixed models including experiment and fungal species and random replicates in the linear predictor. When the fungus did not show any enzyme activity, i.e., the data consisted of only zeros and were not included in the analysis.
Linear mixed models (assuming a normal distribution for the error) were fitted to continuous data sets on foliage and root dry weights, fresh and dry weights of tomato fruits, plant height, and root length, with the inclusion of experiments and the interaction between fungal species and evaluation periods as fixed effects, along with random intercepts and slopes per each group of observations measured over time, given they are correlated. Generalized linear mixed models assuming Poisson distribution for the error were fitted separately to the number of flowers and the number of fruits per plant, including fungal species and experiments as the fixed effects and random replicates in the linear predictor.

Binomial generalized linear mixed models (McCullagh and Nelder, 1989) were fitted to the colonization data (soil, leaves, stems, and roots), including the effects of the experiment and the interaction between fungal species and evaluation periods, and the random effect for the observational level. A colonization success was recorded when fungal growth by either of the isolates occurred. When no colonization could be detected for all observations in a specific treatment, i.e., the data consisted of only zeros, the observations in all plants of the treatment were not included in the analysis. All multiple comparisons of means with their respective 95\% confidence intervals (CIs) were performed with Tukey's HSD test at a significance level of 5\%, using the package “emmeans" (Lenth et al., 2018).

Finally, generalized canonical discriminant analysis for a multivariate linear model was performed with datasets from biochemical assays and plant growth traits to determine the correlation between treatments and response variables. A significant group effect was obtained with the type II MANOVA test using Wilk's test statistic at $P<0.05$, and then correlations between treatment groups and variable vectors were visualized in the biplot. This analysis was performed with the package "candisc" (Friendly and Fox, 2013).

\section{RESULTS}

\section{Growth Promotion Traits Induced by Metarhizium spp. in the Micro-Tom}

The inoculation of MT seedlings with conidial suspensions of $M$. robertsii (ESALQ 1635) or M. humberi (ESALQ 1638) isolates increased plant height over non-inoculated control plants at 10 and 15 DAI (interaction between treatment and time: $F=10.61$, $\mathrm{df}=2,57, P=0.00012$ ) (Figure 1A). At $30 \mathrm{DAI}$, inoculation with $M$. robertsii (ESALQ 1635) significantly increased plant height in relation to plants inoculated with M. humberi (ESALQ 1638) or control plants. A similar result was observed for root length at 30 DAI, in which roots were longer when treated with $M$. robertsii (ESALQ 1635) than non-inoculated plants (interaction between treatment and time: $F=12.02$, $\mathrm{df}=2,57$, $P<0.0001)$

Aerial part and root dry weight increased in inoculated treatments (Aerial part: $F=214.79$, df $=1,42, P<$ 0.0001; Root: $F=142.58$, df $=1,42, P<0.0001)$. Both Metarhizium spp. promoted greater shoot biomass at 15 DAI, while only $M$. robertsii (ESALQ 1635) increased shoot 


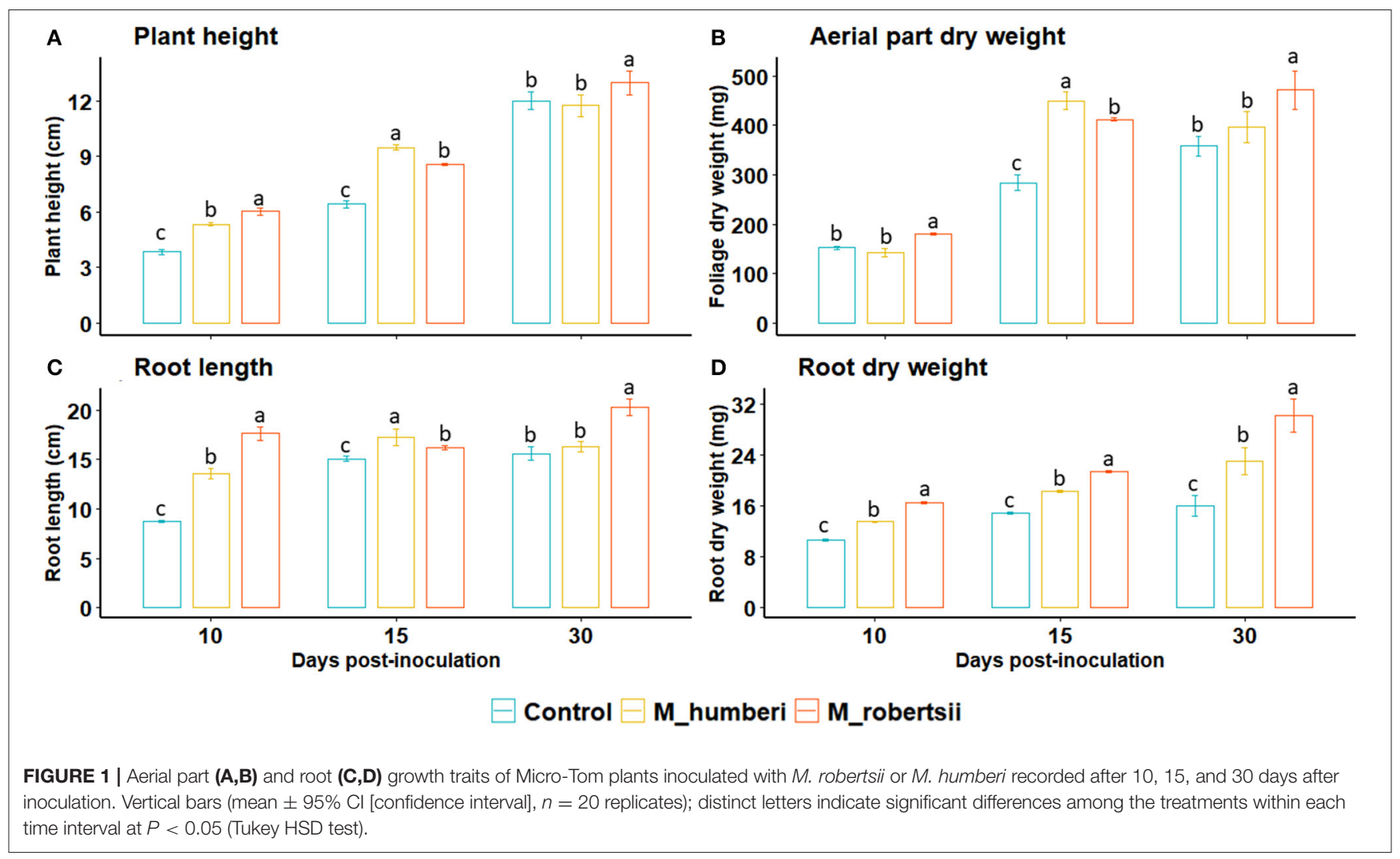

dry matter by day $30(F=21.03$, df $=2,42, P<$ 0.0001) (Figure 1D). Similarly, root dry matter was greater after 10, 15, and 30 DAI in treatments with either fungal species than the control plants $(F=11.44$, df $=2,42$, $P=0.00011$ ) (Figure 1D). In all evaluations, the plants inoculated with $M$. robertsii (ESALQ 1635) had more root dry weight than those inoculated with M. humberi (ESALQ 1638) (Figure 1).

Phenotypic characteristics related to the tomato reproductive stage were measured only at 30 DAI and all were positively impacted by Metarhizium inoculation. Inoculation with the fungi significantly increased the number of flowers $\left(\chi^{2}=25.34\right.$, $\mathrm{df}=2, P<0.0001$ ), with the most flowers attained from plants inoculated with $M$. robertsii (ESALQ 1635), followed by $M$. humberi (ESALQ 1638), and inoculation with either fungus induced more flowering than control plants (Figure 2A). However, the number of fruits per plant was not significantly affected by the treatments $\left(\chi^{2}=2.95\right.$, df $\left.=2, P=0.23\right)$ (Figure 2B). Both fruit fresh and dry weight were significantly increased by inoculation with $M$. robertsii (ESALQ 1635) in comparison to control plants (Fresh weight: $F=3.60$, $\mathrm{df}=2$, $72, P=0.032$; Dry weight: $F=4.79$, df $=2,72, P=0.011$, respectively), but differences were detected between control and M. humberi-inoculated (ESALQ 1638) plants only for fruit fresh weight (Figures 2C,D).

The multivariate linear analysis taking together all variables of tomato growth traits indicates significant variability in plant phenotypic responses mediated by fungal treatments and untreated control (treatment effect: $F=10.42$, df $=16,158$, $P<0.0001)$. The canonical discriminant plot based on all tomato growth variables showed a cluster formed by $M$. robertsii (ESALQ 1635), spatially distant from single clusters formed by $M$. humberi (ESALQ 1638) and the control group (circles indicating the $95 \%$ confidence level of multivariate means $(+)$ do not intersect) (Figure 3). Both groups of M. humberi (ESALQ 1638) and control were placed on the opposite side of $M$. robertsii (ESALQ 1635) when viewing at the first canonical dimension, which corresponded to $86.4 \%$ of all data variability. Thus, this spatial pattern of these groups indicates that $M$. robertsii (ESALQ 1635) distinctly influenced tomato plant growth parameters in relation to M. humberi (ESALQ 1638) and control (untreated) plants. The length and direction of each vector in the biplot indicate the degree of association of the corresponding covariate with the canonical variables and demonstrate the overall superior performance of $M$. robertsii for all measured growth traits in tomato plants. The magnitude of each vector reveals the contribution or importance of each growth trait to each principal canonical component in explaining the clusters formed across treatments. Hence, root dry weight, root length, and aerial part dry weight produced longer vectors and were, therefore, the discriminant factors of these treatments. To a lesser extent, the other growth traits measured in this study also positively contributed to separate $M$. robertsii from the other treatments. 

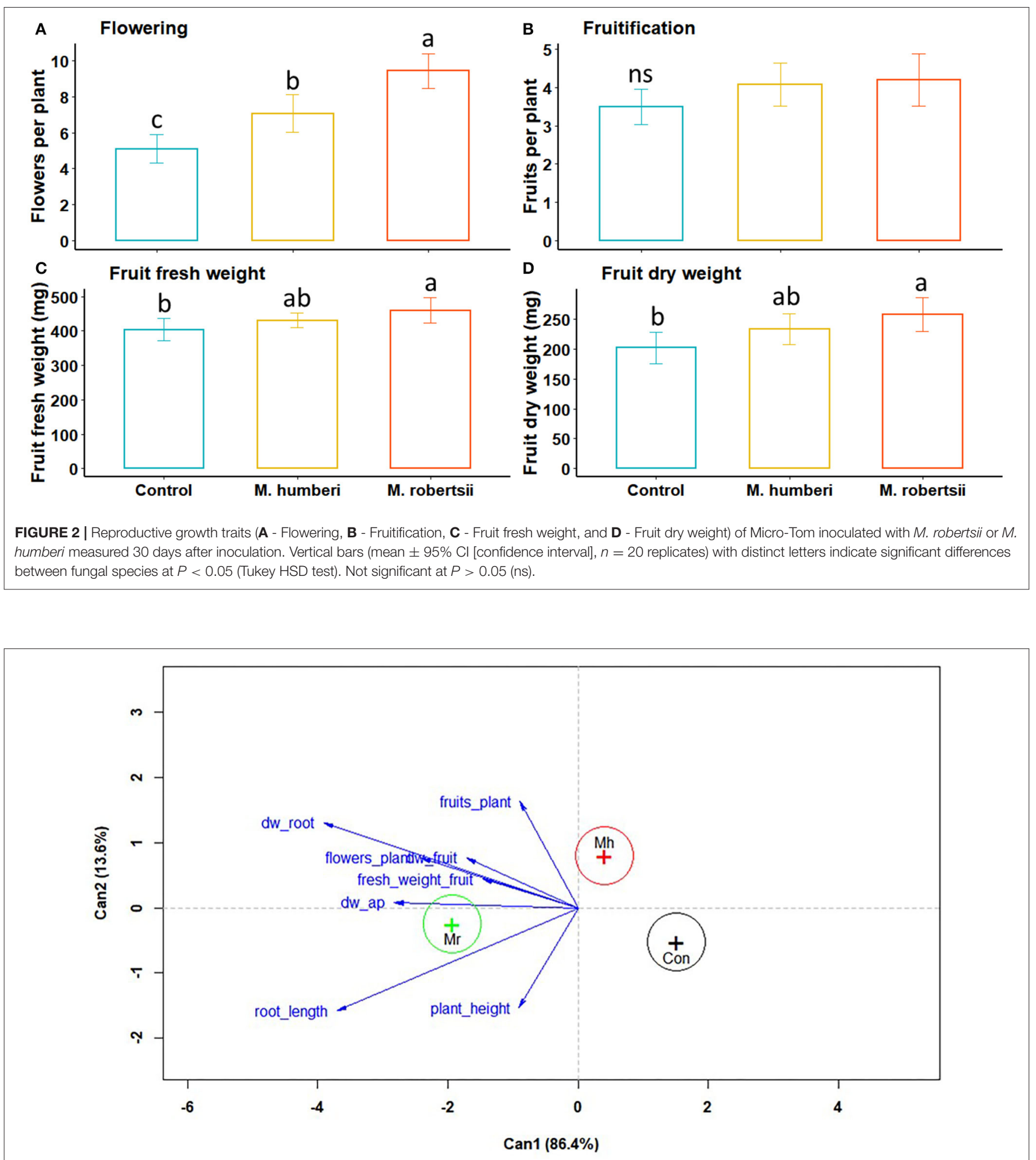

FIGURE 3 | Canonical discriminant plot showing two principal canonical components, in which the blue vectors indicate different magnitudes of correlation with both axes corresponding to plant growth traits recorded at 30 days after inoculation, while circle groups are attributed to fungal species and fungus-free control. (Mr, M. robertsii; Mh, M. humberi; Cont, control). Each fungal species was represented by $n=60$ observations. Vector legends: dw_ap, shoot (aerial part) dry weight; $d w \_r o o t$, root dry weight; $d w \_$fruit, fruit dry weight. 


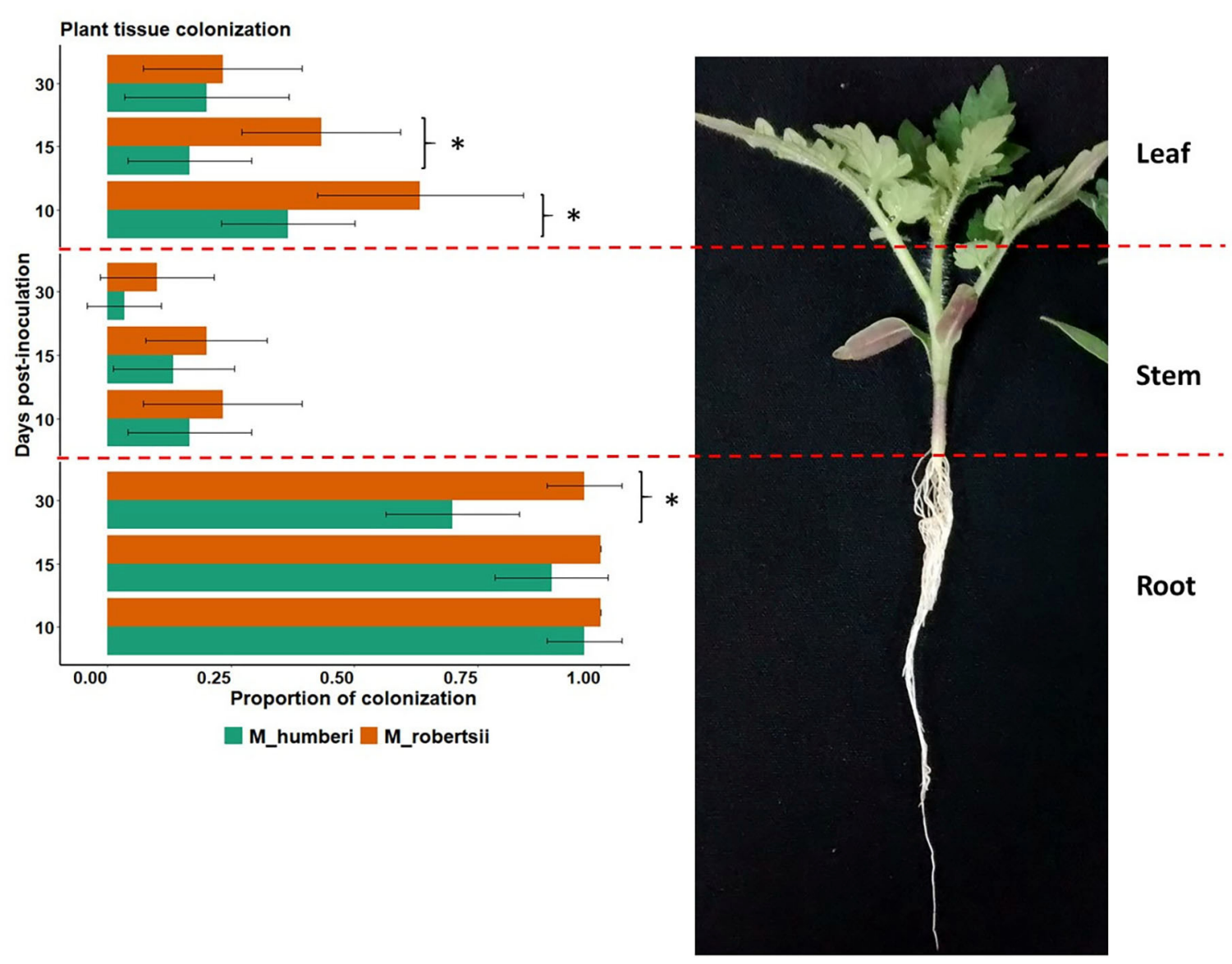

FIGURE 4 | Endophytic colonization of Micro-Tom tissues (leaf, stem, and root) by M. robertsii or M. humberi 10, 15, and 30 days after inoculation. Vertical bars represent the means ( $\pm 95 \% \mathrm{Cl}$ [confidence interval], $n=10$ ), while asterisk $\left(^{*}\right)$ designates significant difference between fungal species at $P<0.05$ (Tukey HSD test).

\section{Re-isolation of Metarhizium spp. From Tissues of the Micro-Tom}

To confirm the infection of MT by the Metarhizium spp., endophytic fungi were re-isolated from inoculated tissues and soil using selective media. Remarkably, both M. robertsii (ESALQ 1635 ) and M. humberi (ESALQ 1638) were able to endophytically colonize all the tomato tissues analyzed (root, stem, and leaf) 1030 DAI using a conidial suspension delivered next to the roots of the tomato seedlings (Figure 4). Our three-way factorial model found no interactions between plant tissues, fungal species, and evaluation periods $(P>0.05)$. However, the difference in colonization among the plant tissues was striking, in which the highest proportion of endophytic colonization was found in the roots, with $70-100 \%$ fungal recovery $\left(\chi^{2}=103.29, \mathrm{df}=3\right.$, $P<0.0001$ ). M. robertsii (ESALQ 1635) appeared to be more successful than M. humberi (ESALQ 1638) in colonizing root tissues evaluated at $30 \mathrm{DAI}$ and leaf tissues at 10 and $15 \mathrm{DAI}$ $\left(\chi^{2}=103.29, \mathrm{df}=2, P<0.0001\right)$; both fungi similarly colonized the stem. The proportion of tomato leaf fragments colonized by M. robertsii (ESALQ 1635) decreased by $63 \%$ with time from 15 to 30 DAI $\left(\chi^{2}=13.60, \mathrm{df}=2, P=0.001\right)$, whereas $M$. humberi (ESALQ 1638), despite its lower colonization levels than $M$. robertsii (ESALQ 1635), varied over time from 36.7 to $16.7 \%$.

From the soil cultivated with tomato, both $M$ robertsii (ESALQ 1635) and M. humberi (ESALQ 1638) were recovered at similar rates from soil samples $\left(\chi^{2}=0.69, \mathrm{df}=1\right.$, $P=0.40)$, corresponding to inoculum densities of $4.4 \times$ $10^{6} \mathrm{CFU} / \mathrm{g}$ and $4.1 \times 10^{6} \mathrm{CFU} / \mathrm{g}$ of soil. The persistence of both species in the soil was unaltered over time $\left(\chi^{2}\right.$ $=0.69, \mathrm{df}=2, P=0.71)$, most likely due to the ubiquitous presence and pronounced colonization of the tomato root system by these fungi. None of the target fungi was retrieved from the plant tissue or soil substrate in the noninoculated control plants, indicating no contamination of potgrown tomato plants by the Metarhizium treatments or a natural occurrence.

\section{Determination of in vitro IAA Production}

M. robertsii (ESALQ 1635) and M. humberi (ESALQ 1638) were able to produce IAA at different extents. The in vitro IAA production greatly varied with fungal species and with the presence or not of tryptophan $(F=17.80$, df $=3,60, P<0.00001)$. Interestingly, IAA synthesis by $M$. 


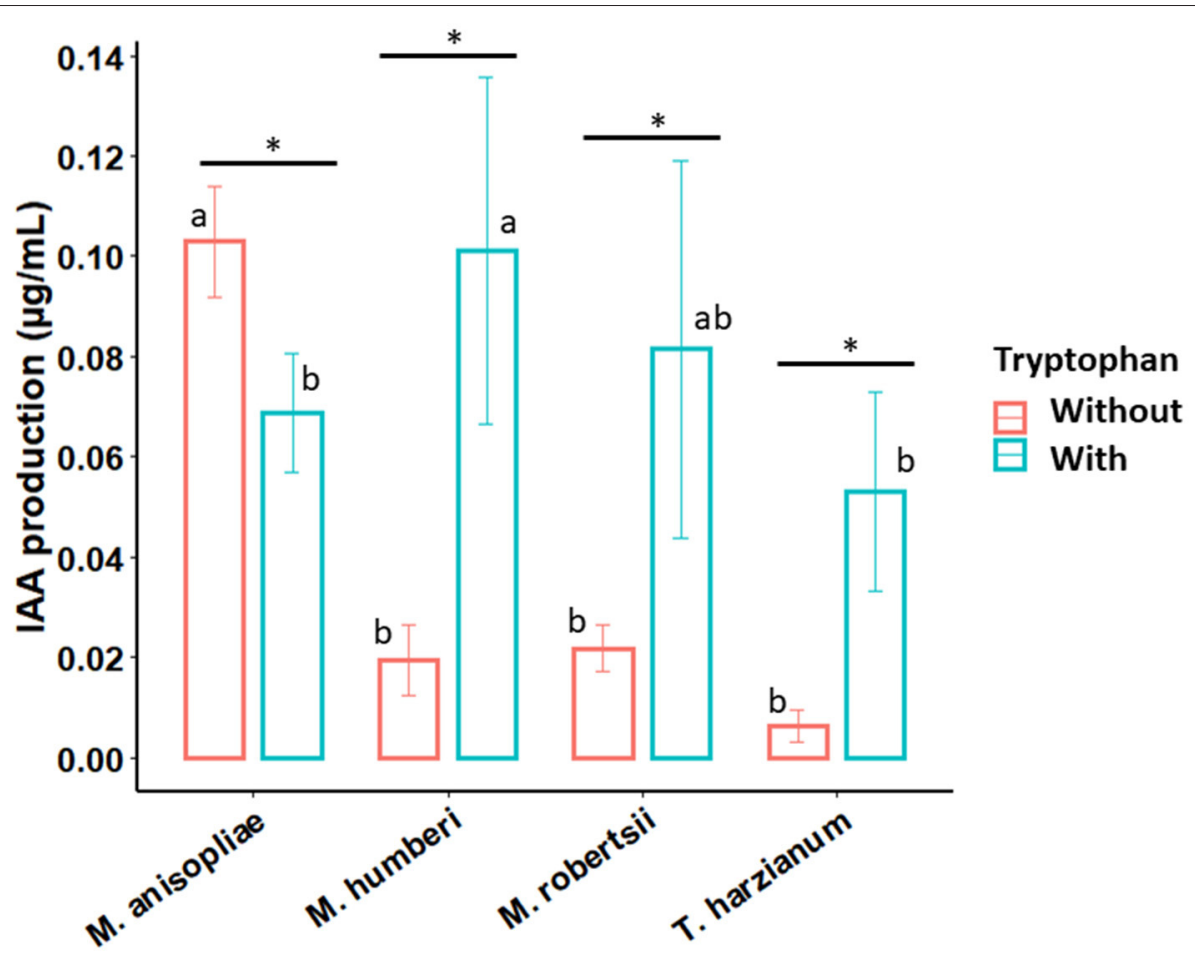

FIGURE 5 | Effect of phenotype and exogenous tryptophan on the ability of Metarhizium species to produce indole-3-acetic acid (IAA) under in vitro conditions. Trichoderma harzianum was used as a positive control for IAA production. Bars (means $\pm 95 \%$ Cls [confidence intervals]) followed by distinct lowercase letters denote significant differences between fungal species for each culture medium (with or without tryptophan), while asterisk $\left({ }^{*}\right)$ indicates significant differences between culture medium supplemented with or without tryptophan within each fungal species. Statistical contrasts were performed with Tukey HSD method at $P<0.05$ ( $n=9$ ).

anisopliae (ESALQ 1669) was significantly boosted without tryptophan and attained the highest concentration level, whereas the other Metarhizium species and T. harzianum (ESALQ 1306) had higher titers when grown in the presence of tryptophan (Figure 5). Thus, the presence of tryptophan was essential for achieving higher IAA synthesis by $M$. humberi (ESALQ 1638), M. robertsii (ESALQ 1638), and T. harzianum (ESALQ 1306), but not for $M$. anisopliae (ESALQ 1669). On the other hand, M. anisopliae (ESALQ 1669) cultures without tryptophan exhibited the highest IAA concentrations, whereas M. humberi (ESALQ 1638) presented higher production of IAA than M. anisopliae (ESALQ 1669) and T. harzianum (ESALQ 1306) when cultured with this IAA precursor.

\section{IAA Signaling by Metarhizium Inoculation}

Compared to the non-inoculated control plants, both $M$. robertsii (ESALQ 1635) and M. humberi (ESALQ 1638) increased the detection of auxin-induced GUS expression in the roots at 10 and 30 DAI (Figure 6). The GUS staining was more intense and covered larger areas of the roots infected by M. robertsii (ESALQ 1635) than M. humberi (ESALQ 1638), suggesting that the former induced more auxin accumulation. Besides, auxin accumulation appeared to be more pronounced in the roots by 30 DAI in relation to day 10 .

\section{Determination of Enzyme Activities and Siderophores}

The phosphate solubilization index was significantly different among Metarhizium spp. and T. harzianum (ESALQ 1306) ( $F=$ 322.56, $\mathrm{df}=3,54, P<0.0001$ ), where the $M$. humberi (ESALQ 1638 ) isolate exhibited the highest phosphatase activity, followed by $M$. anisopliae (ESALQ 1669), T. harzianum (ESALQ 1306), and $M$. robertsii (ESALQ 1635) after 15 DAI. The solubilization index of phosphate ranged from 1.16 to 2.12. The two species of Metarhizium outperformed T. harzianum (ESALQ 1306) in their ability to solubilize phosphate, with the lowest activity achieved for $M$. robertsii (ESALQ 1635) (Figure 7A).

The index used to indirectly estimate phytase activity ranged significantly among the Metarhizium isolates $(F=38.255$, $\mathrm{df}=$ 2, 40, $P<0.0001)$; the $M$. anisopliae isolate attained the higher phytase activity, followed by $M$. robertsii (ESALQ 1635) and M. humberi (ESALQ 1638). The solubilization index of phytate ranged from 1.47 to 1.51 . The isolate of T. harzianum (ESALQ 1306) had null phytase activity, as the fungus did not show any halo zone when grown on medium amended with calcium phytate (Figure 7B).

In vitro production of siderophore was significantly different among the Metarhizium species ( $F=427.69$, df $=2,40$, $P<2.2 \mathrm{e}-16$ ) (Figure 7C). The siderophore secretion index estimated by the size of halo per the size of the colony ranged from 0.99 to 1.62 across Metarhizium species after 15 

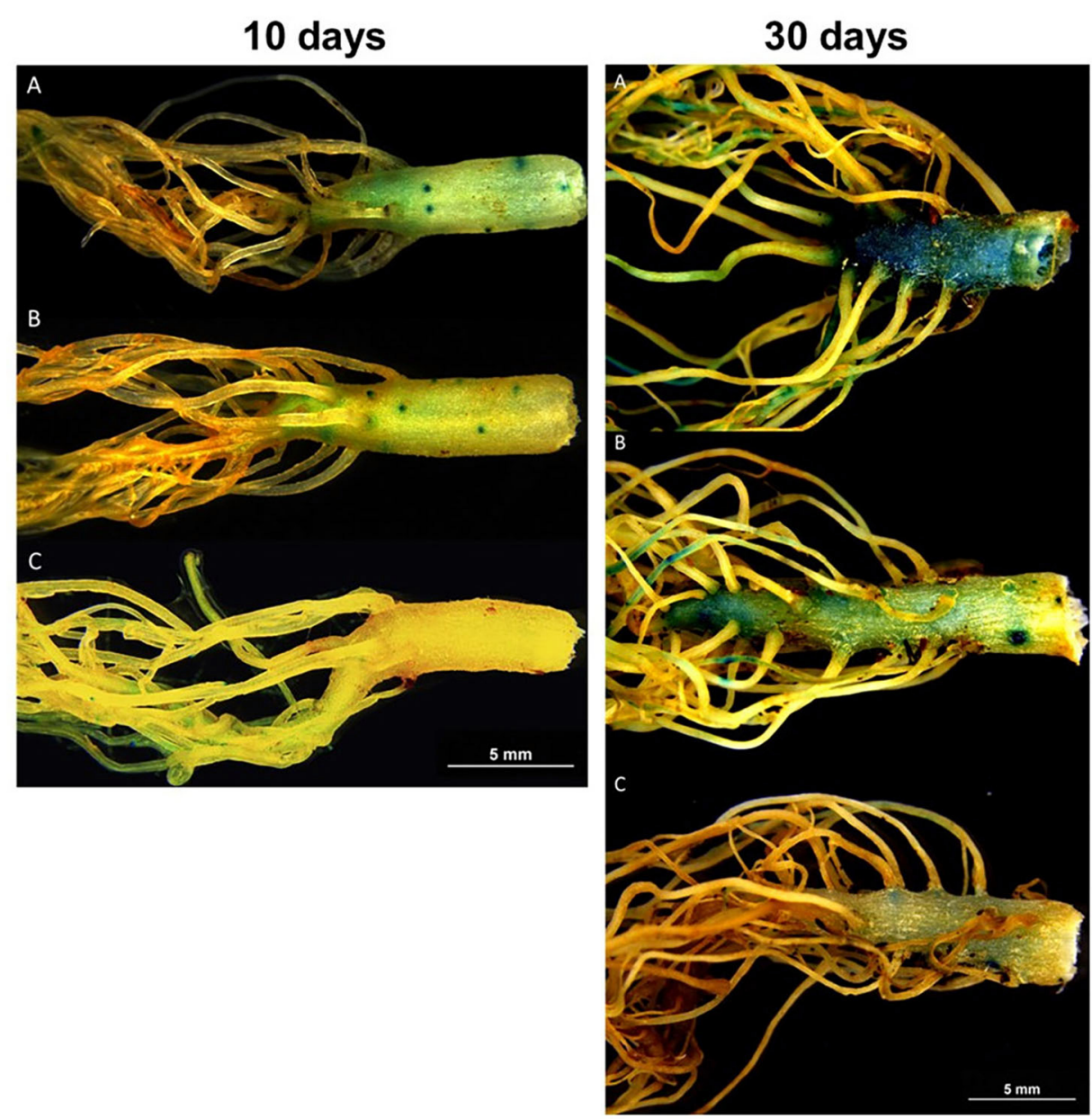

FIGURE 6 | Representative photographs of $\beta$-Glucuronidase (GUS) histochemical staining assay in MT-DR5::GUS, at 10 and 30 days after inoculation with fungal endophytes. Blue stains indicate the specific sites where auxin (IAA) accumulated in the plant tissues as revealed by the histochemical staining with X-Gluc. Seedlings at age 18-21 days were individually inoculated with Metarhizium robertsii (A), Metarhizium humberi (B), or non-inoculated control (C).

days of growth. The isolate of $M$. humberi (ESALQ 1638) outproduced siderophores compared to the other Metarhizium species, whereas the T. harzianum (ESALQ 1306) isolate did not appear to produce such iron-chelating compounds (Figure 7C).

The ability to degrade colloidal chitin by chitinase recorded after 15 days of incubation was significantly affected by fungal species $(F=7315.5$, df $=3,54, P<0.0001)$ (Figure 7D). T. harzianum (ESALQ 1306) exhibited higher chitinase activity than all three Metarhizium species. The second best chitinase producer was the isolate of $M$. robertsii (ESALQ 1635) followed by M. anisopliae (ESALQ 1669) and M. humberi (ESALQ 1638). Chitinase activity indexes varied from 1.49 to 5.80 (Figure 7D).

The multivariate linear analysis fitted to all the biochemical parameters measured for three isolates of Metarhizium spp. and T. harzianum as a positive control significantly captured data variation and revealed quite distinct biochemical profiles among these fungal isolates (treatment effect: $F=19.94, \mathrm{df}=12$, $36, P<0.0001)$. Biochemical traits examined with a canonical discriminant analysis closely grouped M. robertsii (ESALQ 1635) and $M$. humberi (ESALQ 1638) (circles indicate that the 95\% confidence level of multivariate means $(+)$ intersect), mainly due to by the tryptophan-induced IAA and siderophore activities. M. anisopliae (ESALQ 1669) appeared isolated on the opposite side showing a strong positive correlation of IAA (without exogenous tryptophan) and to a less extent, with phosphatase activity. Chitinase activity by far was the strongest trait that separated T. harzianum (ESALQ 1306) from the Metarhizium species (Figure 8).

\section{DISCUSSION}

Overall, our data underpin the endophytic colonization of tomato by both $M$. robertsii and $M$. humberi that remarkably boosted plant growth, demonstrated by the increase in plant height, root length, and dry weight of aerial part and roots compared to the non-inoculated plants. This observation agrees with similar studies using M. anisopliae (García et al., 2011). 

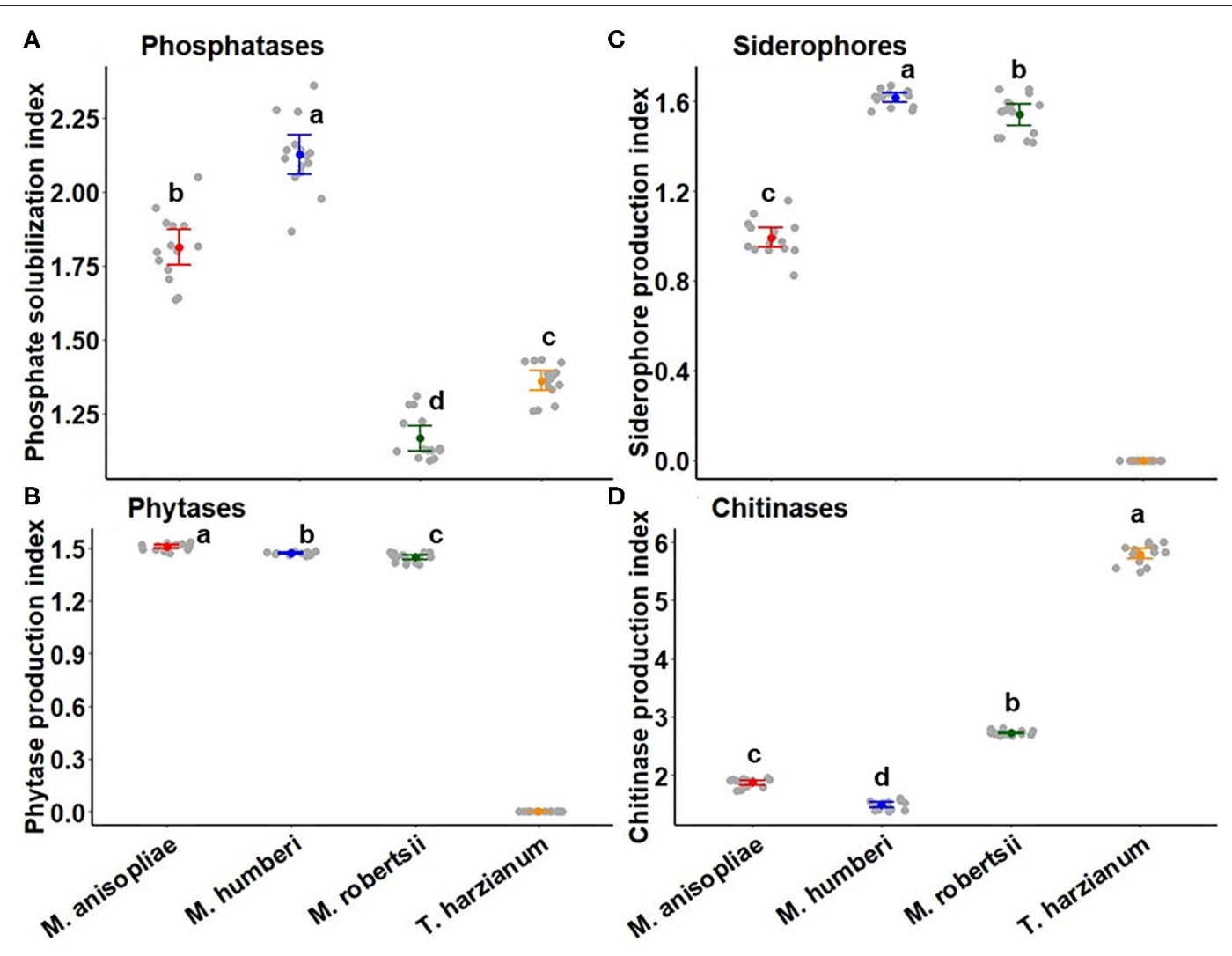

FIGURE 7 | Biochemical profile of Metarhizium species and T. harzianum (as control) by measuring the solubilization or production index after 15 days of growth on specific solid medium to determine the activity of phosphatase (A), phytase (B), siderophore (C), and chitinase (D). Segdots (dots with error bars) indicate means \pm 95\% Cl (confidence intervals), while gray circles represent observed values ( $n=15$ per fungus). Statistical contrasts were performed with Tukey HSD method at $P<$ 0.05 and indicated by different letters. Note: where the mean is zero for some biochemical compounds attributed to T. harzianum, there is no statistical letter for comparison.

Both M. robertsii (ESALQ 1635) and M. humberi (ESALQ 1638) were able to endophytically colonize "Micro-Tom" tissues of roots, leaves, and stems at least 30 DAI. Endophytic fungi notably display preferential tissue colonization, and this preference is commonly attributed to fungal species and isolate, host species, and cultivar, as well as inoculation method and competition by natural soil microbiota. Similarly, García et al. (2011) found a higher ratio of $M$. anisopliae colonization in roots and shoots, but the incidence was limited in leaves. Krell et al. (2018) recently showed the endophytic establishment of $M$. brunneum in stems of tomato plants following delivery of mycelia to the roots, which prompts future studies to address the type of inoculum propagule as a source of variation in the colonization success of plant hosts by endophytic pathogenic fungi.

Several mechanisms underlying the endophytic lifestyle of Metarhizium spp. associated with beneficial effects to plant hosts have been proposed (Harman et al., 2004; Behie and Bidochka, 2014). Nevertheless, the association between endophyte-induced plant growth promotion and biochemical features of Metarhizium involved in plant growth and antagonism toward other fungal pathogens has not been explored. The present study highlights the superior performance of $M$. robertsii (ESALQ 1635) over M. humberi (ESALQ 1638) in promoting tomato growth. It is interesting to note that M. humberi (ESALQ 1638) showed better performance than $M$. robertsii (ESALQ 1635) in the assays for the activity of phosphatases and phytases and the production of siderophores, but the difference between isolates was significant only for phosphatases. M. robertsii (ESALQ 1635) achieved superior performance to $M$. humberi (ESALQ 1638) only for the production of chitinases and in vivo IAA expression estimated by the GUS histochemical assay. A hypothesis is that the higher colonization ability of $M$. robertsii (ESALQ 1635) in tomato MT, revealed by the higher proportion of re-isolation from infected tissues, might be one of the main factors responsible for the stronger growth response of vegetative and reproductive traits.

Indole-3-acetic acid (IAA) is known to regulate plant growth, stimulating seed germination; increasing root development, controlling vegetative growth processes, and affecting photosynthesis and biosynthesis of various metabolites (Spaepen and Vanderleyden, 2011; Rana et al., 2019). The ability to produce IAA is an attribute of several microorganisms, including both plant growth promoters and some plant pathogens (Duca et al., 2014). A recent study was the first to 


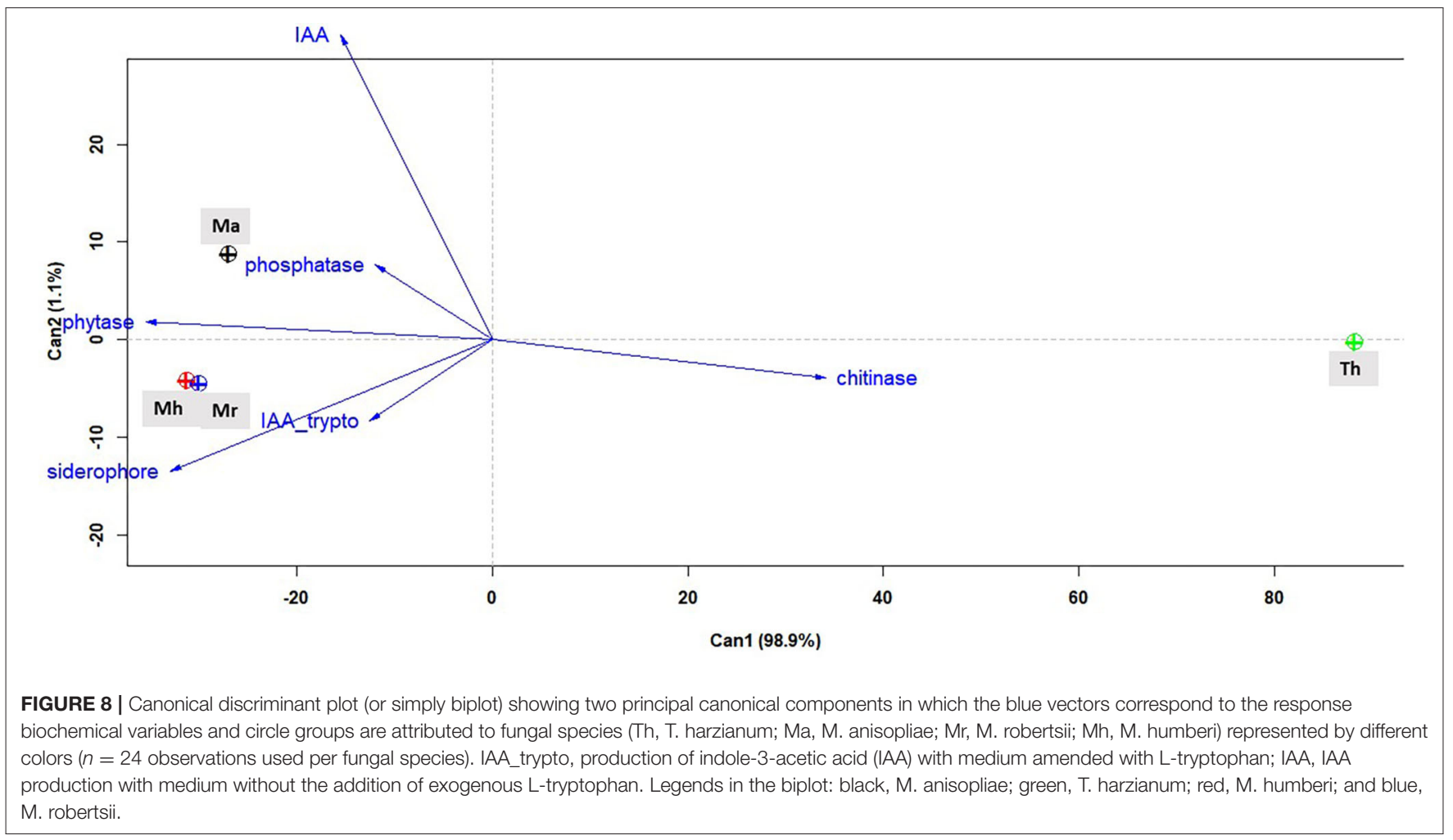

report about IAA production by $M$. robertsii, which promoted root growth in Arabidopsis, and this phenomenon underpinned the importance of auxin in the ability of Metarhizium to stimulate plant growth (Liao et al., 2017). Our study reveals that Brazilian Metarhizium isolates can produce IAA in vitro and this production is higher than for the T. harzianum isolate, a species known for its plant growth stimulation. All three Metarhizium species tested here appeared to produce IAA in vitro in the presence or absence of its precursor tryptophan. Tryptophan is an amino acid found in root exudates and is the main precursor molecule for IAA biosynthesis by both fungi and bacteria (Gupta et al., 2015). Tryptophan appears to be essential for $M$. robertsii (ESALQ 1635) and M. humberi (ESALQ 1638) IAA production, but it is not required for $M$. anisopliae (ESALQ 1669), which curiously produced more IAA in the absence of tryptophan. The coexistence of both tryptophandependent and tryptophan-independent IAA-biosynthetic pathways has been documented for Azospirillum brasilense (Prinsen et al., 1993) and Saccharomyces cerevisiae (Rao et al., 2010). Such behavior displayed by M. anisopliae (ESALQ 1669) for IAA production without the need for tryptophan and its relationship with the plant and hyphal growth warrants further investigation.

The in vitro data on IAA production by the isolates corroborate our findings in the biochemical GUS bioassay, in which the inoculation of DR5::GUS with our isolates of Metarhizium induced auxin-regulated gene expression. Both $M$. robertsii (ESALQ 1635) and M. humberi (ESALQ 1638) increased auxin-induced GUS expression in primary and lateral roots, as well as in root hairs and root tip. These observations suggest that both Metarhizium species induced auxin-regulated gene expression in tomato plants at different extents. Liao et al. (2017) observed that both exogenous synthetic IAA application and $M$. robertsii culture filtrates increased GUS expression in Arabidopsis seedlings, but only in the root tips. The GUS activity varied for the different Metarhizium species, and the highest levels were recorded in roots at 30 DAI. The DR5 system has been widely used, as it provides a high level of accuracy concerning the sensitivity of auxin concentration and is a reliable evaluation for the presence of auxin (Chen et al., 2013). Although M. humberi is a sister lineage of the M. anisopliae s.str (Luz et al., 2019), the results obtained indicated that its performance is more similar to $M$. robertsii than to $M$. anisopliae in many aspects, including the production of key biomolecules that could be associated to endophytic colonization of plants and the antagonism of plant pathogens.

The phosphorus solubilization potential of Metarhizium has only been demonstrated in vitro for $M$. anisopliae by Mishra et al. (2014) and Shukla and Vyas (2014). We also demonstrated that the Brazilian isolates of M. humberi (ESALQ 1638) and $M$. robertsii (ESALQ 1635) can solubilize tricalcium phosphate, an insoluble source of $\mathrm{P}$. The greatest phosphate solubilization was attributed to $M$. humberi (ESALQ 1638) followed by $M$. anisopliae (ESALQ 1669), while the solubilization index of $M$. robertsii (ESALQ 1635) was very close to $T$. harzianum (ESALQ 1306). The microbial phosphorus solubilization helps to make phosphorus available for plants to uptake. After nitrogen $(\mathrm{N})$, phosphorus $(\mathrm{P})$ is the most important element in plant nutrition and acts in major plant metabolic processes, such as photosynthesis and respiration (Khan et al., 2010). Plants 
absorb phosphate only as monobasic $\left(\mathrm{H}_{2} \mathrm{PO}_{4}^{-}\right)$and dibasic $\left(\mathrm{HPO}_{4}^{-2}\right)$ ions, but most of the $\mathrm{P}$ present in the soil is insoluble, immobilized, or precipitated, and thus these $\mathrm{P}$ forms are unavailable for plants (Gouda et al., 2018). Soil microorganisms can solubilize insoluble phosphorus by producing organic exudates, organic acids, acid phosphatases, or enzymes, such as phytases, making $\mathrm{P}$ available to be acquired by plants (Jha and Saraf, 2015).

The Metarhizium isolates tested can produce phytase, an enzyme able to decompose phytic acid. Between $60-80 \%$ of organic phosphate in the soil is inositol-hexakisphosphate, also known as phytic acid or phytate (Schachtman et al., 1998). This enzyme has been detected in microorganisms like fungi but had never been identified in Metarhizium species. Our study proved for the first time that $M$. anisopliae (ESALQ 1669), M. robertsii (ESALQ 1635), and M. humberi (ESALQ 1638) produced high titers of phytase. The isolate of $T$. harzianum (ESALQ 1306) did not produce this enzyme. These data highlight the potential of Metarhizium to improve the $\mathrm{P}$ content and to enhance plant growth, but further studies should be developed to check the importance of phytases in plant growth promotion by entomopathogenic endophytic fungi in the field.

Iron $(\mathrm{Fe})$ is one of the most abundant elements on earth and an essential micronutrient for several living organisms. Siderophores play an important role in iron uptake by plants and siderophore-secreting microorganisms inside plant tissues act in the transport of $\mathrm{Fe}^{3+}$ for the synthesis of ATP, chlorophyll, and DNA, contributing to plant growth and yield (Schwyn and Neilands, 1987; Neilands, 1995; Beneduzi et al., 2012). Indirectly, siderophore production by plant growth promoting microorganisms can avoid the proliferation of plant pathogens through the sequestration of $\mathrm{Fe}^{3+}$ around the rhizosphere (Gupta et al., 2015; Jha and Saraf, 2015). Some studies indicated that the siderophore production by $M$. robertsii can play an important role during insect infection and fungal virulence, as well as alleviate the sensitivity of conidia and microsclerotium to oxidative stress and sustain their development under ironlimited conditions (Krasnoff et al., 2014; Donzelli et al., 2015; Li et al., 2016; Sbaraini et al., 2016; Raya-Díaz et al., 2017). Our study was the first to report siderophore synthesis by $M$. anisopliae (ESALQ 1669) and M. humberi (ESALQ 1638), and our results indicate that siderophore production by some Metarhizium species could be involved in plant growth promotion.

The complexity of chitinases isolated from Metarhizium has been extensively studied. Several studies have shown that this fungus produces extracellular chitinases and correlate their importance during the fungal invasion in insect hosts (St. Leger et al., 1991, 1993). However, the role of chitinases is not clearly understood in Metarhizium plant colonization and growth. Chitinases are produced in a large number of microbial endophytes and can contribute to plant growth promotion, both directly and indirectly. This group of enzymes has been studied for their potential for biocontrol of phytophagous nematodes and plant pathogenic fungi (Gan et al., 2007). Few studies have examined the potential of chitinases involved in the antagonistic effects of Metarhizium to plant pathogens or even plant-parasitic nematodes. A large range of Brazilian Metarhizium isolates can antagonize in vitro the sugarcane plant pathogens Fusarium moniliforme and Colletotrichum falcatum (A.C. Siqueira, unpublished data). Thus, chitinase and siderophore activities displayed by Metarhizium isolates may be good proxies for the selection of good antagonists against other fungal plant pathogens. However, it is important to point out that the biochemical characterization of fungal isolates determined in vitro does not always reflect the outcomes for in situ antagonism or plant growth promotion.

The two isolates of $M$. robertsii (ESALQ 1635) and $M$. humberi (ESALQ 1638) are currently under registration in Brazil as the active ingredients of one biopesticide product. Here, were demonstrated that both isolates have interesting and complementary beneficial attributes, such as the biochemical metabolic traits, endophytic colonization, and stimulation of plant growth. This study envisions the first endophytic Metarhizium-based multifunctional bioproduct as an innovative strategy for plant stimulation and pest biocontrol in agriculture, which may ultimately lead to increased crop productivity and less reliance on chemical inputs.

\section{DATA AVAILABILITY STATEMENT}

The datasets generated for this study are available on request to the corresponding author.

\section{AUTHOR CONTRIBUTIONS}

AS, CG, and ÍD conceived the idea and designed the experiments. AS, CG, and JM performed the experiments and acquired data. GM analyzed the data. AS, GM, and ID wrote the manuscript. JM, MQ, and AF contributed to the manuscript write and revisions. All authors have read and approved the final manuscript.

\section{FUNDING}

This study was financed in part by the Coordenação de Aperfeiçoamento de Pessoal de Nível Superior-Brasil (CAPES)-Finance Code 001 and EMBRAPII Empresa Brasileira de Pesquisa e Inovação Industrial-(Project number PESQ-18040001).

\section{ACKNOWLEDGMENTS}

We thank Danielle Camargo Scotton for use of the equipment in the lab and for assisting on growing Micro-Tom plants. Roberto Gaioski Jr. assisted in the establishment and evaluation of experiments in the greenhouse. Alene Alder-Rangel reviewed the language in the manuscript. This manuscript was part of the Ph.D. thesis of the AS. 


\section{REFERENCES}

Agrawal, T., and Kotasthane, A. S. (2012). Chitinolytic assay of indigenous Trichoderma isolates collected from different geographical locations of Chhattisgarh in Central India. Springerplus 1, 1-22. doi: $10.1186 / 2193-1801-1-73$

Barrow, J. R., and Osuna, P. (2002). Phosphorus solubilization and uptake by dark septate fungi in fourwing saltbush, Atriplex canescens (Pursh) Nutt. J. Arid Environ. 51, 449-459. doi: 10.1006/jare.2001.0925

Bartholdy, B. A., Berreck, M., and Haselwandter, K. (2001). Hydroxamate siderophore synthesis by Phialocephala fortinii, a typical dark septate fungal root endophyte. BioMetals 14, 33-42. doi: 10.1023/A:1016687021803

Behie, S. W., and Bidochka, M. J. (2014). Ubiquity of insect-derived nitrogen transfer to plants by endophytic insect-pathogenic fungi: an additional branch of the soil nitrogen cycle. Appl. Environ. Microbiol. 80, 1553-1560. doi: 10.1128/AEM.03338-13

Behie, S. W., Jones, S. J., and Bidochka, M. J. (2015). Plant tissue localization of the endophytic insect pathogenic fungi Metarhizium and Beauveria. Fungal Ecol. 13, 112-119. doi: 10.1016/j.funeco.2014.08.001

Beneduzi, A., Ambrosini, A., and Passaglia, L. M. P. (2012). Plant growthpromoting rhizobacteria (PGPR): Their potential as antagonists and biocontrol agents. Genet. Mol. Biol. 4, 1044-1051. doi: 10.1590/S1415-47572012000600020

Blanco, C., Ritzenthaler, P., and Mata-Gilsinger, M. (1982). Cloning and endonuclease restriction analysis of uidA and uidR genes in Escherichia coli K-12: Determination of transcription direction for the uidA gene. J. Bacteriol. 149, 587-594. doi: 10.1128/JB.149.2.587-594.1982

Bose, A., Shah, D., and Keharia, H. (2013). Production of indole-3-acetic-acid (IAA) by the white rot fungus Pleurotus ostreatus under submerged condition of Jatropha seedcake. Mycology 4, 103-111. doi: 10.1080/21501203.2013.823891

Botelho, A. B. R. Z., Alves-pereira, A., Colonhez, R., Imaculada, M., and Delalibera, I. (2019). Metarhizium species in soil from Brazilian biomes : a study of diversity, distribution, and association with natural and agricultural environments. Fungal Ecol. 41, 289-300. doi: 10.1016/j.funeco.2019.07.004

Caldwell, B. A., Jumpponen, A., and Trappe, J. M. (2000). Mycological Society of America Utilization of major detrital substrates by dark-septate, root endophytes. Mycologia 92, 230-232. doi: 10.1080/00275514.2000.12061149

Chen, Y., Yordanov, Y. S., Ma, C., Strauss, S., and Busov, V. B. (2013). DR5 as a reporter system to study auxin response in Populus. Plant Cell Rep. 32, 453-463. doi: 10.1007/s00299-012-1378-x

Dalai, R. C. (1977). Soil organic phosphorus. Adv. Agron. 29, 83-117. doi: 10.1016/S0065-2113(08)60216-3

Donzelli, B. G. G., Gibson, D. M., and Krasnoff, S. B. (2015). Intracellular siderophore but not extracellular siderophore is required for full virulence in Metarhizium robertsii. Fungal Genet. Biol. 82, 56-68. doi: 10.1016/j.fgb.2015.06.008

Duca, D., Lorv, J., Patten, C. L., Rose, D., and Glick, B. R. (2014). Indole-3-acetic acid in plant-microbe interactions. Antonie van Leeuwenhoek. Int. J. Gen. Mol. Microbiol. 106, 85-125. doi: 10.1007/s10482-013-0095-y

Elsharkawy, M. M., and El-Khateeb, N. M. M. (2019). Antifungal activity and resistance induction against Sclerotium cepivorum by plant growthpromoting fungi in onion plants. Egypt. J. Biol. Pest Control. 29:68. doi: 10.1186/s41938-019-0178-9

Etesami, H., Alikhani, H. A., and Hosseini, H. M. (2015). Indole-3-acetic acid (IAA) production trait, a useful screening to select endophytic and rhizosphere competent bacteria for rice growth promoting agents. MethodsX. 2, 72-78. doi: 10.1016/j.mex.2015.02.008

Friendly, M., and Fox, J. (2013). Candisc: Visualizing Generalized Canonical Discriminant and Canonical Correlation Analysis (Version 1.0). Retrieved from http://CRAN.R-project.org/package=candisc.

Furtado, B. U., Szymańska, S., and Hrynkiewicz, K. (2019). A window into fungal endophytism in Salicornia europaea: deciphering fungal characteristics as plant growth promoting agents. Plant Soil. 445, 577-594. doi: 10.1007/s11104-019-04315-3

Gan, Z., Yang, J., Tao, N., Liang, L., Mi, Q., Li, J., et al. (2007). Cloning of the gene Lecanicillium psalliotae chitinase Lpchil and identification of its potential role in the biocontrol of root-knot nematode Meloidogyne incognita. Appl. Microbiol. Biotechnol. 76, 1309-1317. doi: 10.1007/s00253-007-1111-9
García, J. E., Posadas, J. B., Perticari, A., and Lecuona, R. E. (2011). Metarhizium anisopliae (Metschnikoff) sorokin promotes growth and has endophytic activity in tomato plants. Adv. Biol. Res. (Rennes). 5, 22-27.

Ghosh, P., Rathinasabapathi, B., and Ma, L. Q. (2015). Phosphorus solubilization and plant growth enhancement by arsenic-resistant bacteria. Chemosphere 134, 1-6. doi: 10.1016/j.chemosphere.2015.03.048

Gordon, S. A., and Weber, R. P. (1951). Colorimetric estimation of indole-3-acetic acid. Plant Physiol. 26, 192-195. doi: 10.1104/pp.26.1.192

Gouda, S., Kerry, R. G., Das, G., Paramithiotis, S., Shin, H. S., and Patra, J. K. (2018). Revitalization of plant growth promoting rhizobacteria for sustainable development in agriculture. Microbiol. Res. 206, 131-140. doi: 10.1016/j.micres.2017.08.016

Grobelak, A., Napora, A., and Kacprzak, M. (2015). Using plant growthpromoting rhizobacteria (PGPR) to improve plant growth. Ecol. Eng. 84, 22-28. doi: 10.1016/j.ecoleng.2015.07.019

Gupta, G., Parihar, S. S., Ahirwar, N. K., Snehi, S. K., and Singh, V. (2015). Plant Growth Promoting Rhizobacteria (PGPR): current and future prospects for development of sustainable agriculture. J. Microb. Biochem. Technol. 7, 96-102. doi: 10.4172/1948-5948.1000188

Harman, G. E., Howell, C. R., Viterbo, A., Chet, I., and Lorito, M. (2004). Trichoderma species - Opportunistic, avirulent plant symbionts. Nat. Rev. Microbiol. 2, 43-56. doi: 10.1038/nrmicro797

Howson, S. J., and Davis, R. P. (1983). Production of phytate-hydrolysing enzyme by some fungi. Enzyme Microb. Technol. 5, 377-382. doi: 10.1016/0141-0229(83)90012-1

Jaber, L. R., and Ownley, B. H. (2017). Can we use entomopathogenic fungi as endophytes for dual biological control of insect pests and plant pathogens? doi: 10.1016/j.biocontrol.2017.01.018

Jefferson, R. A., Kavanagh, T. A., and Bevan, M. W. (1987). GUS fusions: Bglucuronidase as a sensitive and versatile gene fusion marker in higher plants. EMBO J. 6, 3901-3907. doi: 10.1002/j.1460-2075.1987.tb02730.x

Jha, C. K., and Saraf, M. (2015). Plant Growth Promoting Rhizobacteria (PGPR): a review. J. Agric. Res. Dev. 5, 0108-0119.

Kauss, H., Jeblick, W., and Young, D. H. (1983). Chitin Deacetylase from the Plant Pathogen Colletotrichum lindemuthianum. Plant Sci. Lett. 28, 231-236. doi: 10.1016/S0304-4211(83)80014-5

Khan, M. S., Zaidi, A., Ahemad, M., Oves, M., and Wani, P. A. (2010). Plant growth promotion by phosphate solubilizing fungi - current perspective. Arch. Agron. Soil Sci. 56, 73-98. doi: 10.1080/03650340902806469

Kobayashi, T., and Nishizawa, N. K. (2012). Iron uptake, translocation, and regulation in higher plants. Annu. Rev. Plant Biol. 63, 131-152. doi: 10.1146/annurev-arplant-042811-105522

Krasnoff, S. B., Keresztes, I., Donzelli, B. G. G., and Gibson, D. M. (2014). Metachelins, mannosylated and N-oxidized coprogen-type siderophores from Metarhizium robertsii. J. Nat. Prod. 77, 1685-1692. doi: 10.1021/np50 0300s

Krell, V., Unger, S., Jakobs-Schoenwandt, D., and Patel, A. V. (2018). Endophytic Metarhizium brunneum mitigates nutrient deficits in potato and improves plant productivity and vitality. Fungal Ecol. 34, 43-49. doi: 10.1016/j.funeco.2018.04.002

Lenth, R., Singman, H., Love, J., Buerkner, P., and Herve, M. (2018). Emmeans. R Packag. version 1.15-15 34, 216-221.

Li, Y., Wang, Z., Liu, X., Song, Z., Li, R., Shao, C., et al. (2016). Siderophore biosynthesis but not reductive iron assimilation is essential for the dimorphic fungus Nomuraea rileyi conidiation, dimorphism transition, resistance to oxidative stress, pigmented microsclerotium formation, and virulence. Front. Microbiol. 7, 1-19. doi: 10.3389/fmicb.2016.00931

Liao, X., Lovett, B., Fang, W., and St Leger, R. J. (2017). Metarhizium robertsii produces indole-3-acetic acid, which promotes root growth in Arabidopsis and enhances virulence to insects. Microbiol. (United Kingdom) 163, 980-991. doi: 10.1099/mic. 0.000494

Lima, J. E., Benedito, V. A., Figueira, A., and Peres, L. E. P. (2009). Callus, shoot and hairy root formation in vitro as affected by the sensitivity to auxin and ethylene in tomato mutants. Plant Cell Rep. 28, 1169-1177. doi: 10.1007/s00299-009-0718-y

Luz, C., Rocha, L. F. N., Montalva, C., Souza, D. A., Botelho, B. R. Z., Lopes, R. B., et al. (2019). Metarhizium humberi sp. nov. (Hypocreales: Clavicipitaceae), 
a new member of the PARB clade in the Metarhizium anisopliae complex from Latin America. J. Invertebr. Pathol. 166:107216. doi: 10.1016/j.jip.2019. 107216

Mart,í, E., Carrera, E., Ruiz-Rivero, O., and García-Martínez, J. L. (2010). Hormonal regulation of tomato gibberellin 20-oxidasel expressed in Arabidopsis. J. Plant Physiol. 167, 1188-1196. doi: 10.1016/j.jplph.2010.03.019

McCullagh, P., and Nelder, J. A. (1989). Generalized Linear Models. 2nd ed. London: Chapman and Hall/CRC. doi: 10.1007/978-1-4899-3242-6

Meissner, R., Jacobson, Y., Melamed, S., Levyatuv, S., Shalev, G., Ashri, A., et al. (1997). A new model system for tomato genetics. Plant J. 12, 1465-1472. doi: 10.1046/j.1365-313x.1997.12061465.x

Miles, A. A., Misra, S. S., and Irwin, J. O. (1938). The estimation of the bactericidal power of the blood. J. Hyg. (Lond). 38, 732-749. doi: $10.1017 /$ S002217240001158X

Mishra, V. K., Passari, A. K., Kumar, K. S., and Singh, B. P. (2014). Molecular characterization of phosphate solubilizing fungi associated with rhizospheric soils of banana. Sci. Technol. J. 2, 57-66.

Moral, R. A., Hinde, J., and Demétrio, C. G. B. (2017). Half-normal plots and overdispersed models in R: the hnp package. J. Stat. Softw. 81, 1-23. doi: $10.18637 /$ jss.v081.i10

Neilands, J. B. (1995). Siderophores : structure and function of microbial iron transport compounds siderophores: structure and function of microbial iron transport compounds *. 270, 26723-26726. doi: 10.1074/jbc.270.45.26723

Nieto-Jacobo, M. F., Steyaert, J. M., Salazar-Badillo, F. B., Vi Nguyen, D., Rostás, M., Braithwaite, M., et al. (2017). Environmental growth conditions of Trichoderma spp. Affects indole acetic acid derivatives, volatile organic compounds, and plant growth promotion. Front. Plant Sci. 8, 1-18. doi: 10.3389/fpls.2017.00102

Oliveira, D. G. P., Pauli, G., Mascarin, G. M., and Delalibera, I. (2015). A protocol for determination of conidial viability of the fungal entomopathogens Beauveria bassiana and Metarhizium anisopliae from commercial products. J. Microbiol. Methods 119, 44-52. doi: 10.1016/j.mimet.2015.09.021

Parmar, H. Y., and Chakraborty, H. (2016). Effect of siderophore on plant growth promotion. Int. J. Appl. Pure Sci. Agric. 2, 60-69.

Parsa, S., Ortiz, V., and Vega, F. E. (2013). Establishing fungal entomopathogens as endophytes: towards endophytic biological control. J. Vis. Exp. 11, 1-5. doi: $10.3791 / 50360$

Payne, S. M. (1994). Detection, isolation, and characterization of siderophores. Methods Enzymol. 235, 329-344. doi: 10.1016/0076-6879(94)35151-1

Pikovskaya, R. (1948). Mobilization of phosphorus in soil connection with the vital activity of some microbial species. Microbiology 17, 362-370.

Prinsen, E., Costacurta, A., Michiels, C., Vanderleyden, J., and Van Onckelen, H. (1993). Azospirillum brasilense indole-3-acetic acid biosynthesis: evidence for a non-tryptophan-dependent pathway. Mol. Plant-Microbe Interact. 6, 609-615. doi: 10.1094/M.P.M.I.-6-609

R Core Team (2018). R: A Language and Environment for Statistical Computing. R Foundation for Statistical Computing, Vienna. Available online at: https:// www.R-project.org.

Rana, K. L., Kour, D., Sheikh, I., and Yadav, N. (2019). Advances in Endophytic Fungal Research. New York, NY: Springer International Publishing. Available online at: https://www.springer.com/gp/book/9783030035884

Rao, R. P., Hunter, A., Kashpur, O., and Normanly, J. (2010). Aberrant synthesis of indole-3-acetic acid in Saccharomyces cerevisiae triggers morphogenic transition, a virulence trait of pathogenic fungi. Genetics 185, 211-220. doi: 10.1534/genetics.109.112854

Raya-Díaz, S., Sánchez-Rodríguez, A. R., Segura-Fernández, J. M., Del Campillo, M. D. C., and Quesada-Moraga, E. (2017). Entomopathogenic fungi-based mechanisms for improved Fe nutrition in sorghum plants grown on calcareous substrates. PLoS ONE. 12, 1-28. doi: 10.1371/journal.pone.0185903
Rezende, J. M., Zanardo, A. B. R., da Silva Lopes, M., Delalibera, I., and Rehner, S. A. (2015). Phylogenetic diversity of Brazilian Metarhizium associated with sugarcane agriculture. BioControl 60, 495-505. doi: 10.1007/s10526-015-9656-5

Roberts, D. W., and St. Leger, R. J. (2004). Metarhizium spp., cosmopolitan insect-pathogenic fungi: mycological aspects. Adv. Appl. Microbiol. 54, 1-70. doi: 10.1016/S0065-2164(04)54001-7

Rout, G. R., and Sahoo, S. (2015). Role of iron in plant growth and metabolism. Rev. Agric. Sci. 3, 1-24. doi: 10.7831/ras.3.1

Samuels, K. D. Z., Heale, J. B., and Llewellyn, M. (1989). Characteristics relating to the pathogenicity of Metarhizium anisopliae toward Nilaparvata lugens. J. Invertebr. Pathol. 53, 25-31. doi: 10.1016/0022-2011(89)90070-0

Sbaraini, N., Guedes, R. L. M., Andreis, F. C., Junges, Â., de Morais, G. L., Vainstein, M. H., et al. (2016). Secondary metabolite gene clusters in the entomopathogen fungus Metarhizium anisopliae: genome identification and patterns of expression in a cuticle infection model. BMC Genomics 17:736. doi: 10.1186/s12864-016-3067-6

Schachtman, D. P., Reid, R. J., and Ayling, S. M. (1998). Phosphorus uptake by plants: from soil to cell. Plant Physiol. 116, 447-453. doi: 10.1104/pp. 116.2.447

Schwyn, B., and Neilands, J. B. (1987). Universal chemical assay for the detection and determination of siderophores. Anal. Biochem. 160, 47-56. doi: 10.1016/0003-2697(87)90612-9

Scott and Harbaugh (1989). Micro Tom-a Miniature Dwarf Tomato. Agricultural Experiment Station, Institute of Food and Agricultural Sciences, University of Florida. Available online at: https://books.google.com.br/books?id=y3DMQEACAAJ.

Shukla, R. M., and Vyas, R. V. (2014). Phosphate solubilizing efficiency of Mycopesticides. Int. J. Agric. Environ. Biotechnol. 7:705. doi: 10.5958/2230-732X.2014.01378.3

Singh, B., and Satyanarayana, T. (2011). Microbial phytases in phosphorus acquisition and plant growth promotion. Physiol. Mol. Biol. Plants. 17, 93-103. doi: 10.1007/s12298-011-0062-x

Spaepen, S., and Vanderleyden, J. (2011). Auxin and Plant-Microbe Interactions, 1-13. doi: $10.1101 /$ cshperspect.a001438

St. Leger, R. J., Cooper, R. M., and Charnley, A. K. (1991). Characterization of chitinase and chitobiase produced by the entomopathogenic fungus Metarhizium anisopliae. J. Invertebr. Pathol. 58, 415-426. doi: 10.1016/0022-2011(91)90188-V

St. Leger, R. J., Staples, R. C., and Roberts, D. W. (1993). Entomopathogenic isolates of Metarhizium anisopliae, Beauveria bassiana, and Aspergillus flavus produce multiple extracellular chitinase isozymes. J. Invertebr. Pathol. 61, 81-84. doi: 10.1006/jipa.1993.1014

Vega, F. E. (2018). The use of fungal entomopathogens as endophytes in biological control: a review. Mycologia 110, 4-30. doi: 10.1080/00275514.2017.1418578

Vidal, S., and Jaber, L. R. (2015). Entomopathogenic fungi as endophytes: Plantendophyte-herbivore interactions and prospects for use in biological control. Curr. Sci. 109, 46-54.

Conflict of Interest: The authors declare that the research was conducted in the absence of any commercial or financial relationships that could be construed as a potential conflict of interest.

Copyright (๑) 2020 Siqueira, Mascarin, Gonçalves, Marcon, Quecine, Figueira and Delalibera. This is an open-access article distributed under the terms of the Creative Commons Attribution License (CC BY). The use, distribution or reproduction in other forums is permitted, provided the original author(s) and the copyright owner(s) are credited and that the original publication in this journal is cited, in accordance with accepted academic practice. No use, distribution or reproduction is permitted which does not comply with these terms. 